\title{
Research and Testing Without Animals: Where Are We Now and Where Are We Heading?
}

\author{
Thomas Hartung \\ Director, Center for Alternatives to Animal Testing, John Hopkins University, \\ Baltimore, MD, United States
}

\section{Introduction}

I don't think there's much point in bemoaning the state of the world unless there's some way you can think of to improve it. Otherwise, don't bother writing a book; go and find a tropical island and lie in the sun.

PETER SINGER

Experiments involving non-human animals (hereinafter referred to as animals) were the predominant technology in the life sciences from the 1920s to the 1970s. Increasingly, animal-based procedures have been complemented and superseded by other approaches; yet, they still have an enormous reputation as an apparent definitive answer to many scientific and, especially, regulatory questions. They have been questioned first for ethical reasons: Can we justify making animals suffer for scientific inquiry? Simply said, people have different views on this question, but the general public views animal experimentation more and more critically. The animal research community has sought a compromise between those who would like to see the end to the use of animals sooner rather than later, and those who think animal research is indispensable. The societal response has included regulation and oversight of animal experiments (e.g., requiring formal justifications and permission), as well as support for the development of alternative methods.

\section{Progress in Legislation}

Building on the legislation of some of the more progressive Member States, the European Union (EU) has twice advanced the legislative oversight of animal experimentation and the push for alternative methods. Already in 1986, European lawmakers reasoned that harmonized animal testing legislation

(C) THOMAS HARTUNG, 2019 | DOI:10.1163/9789004391192_029

This is an open access chapter distributed under the terms of the prevailing CC-BY-NC License at the time 99004391192 of publication. 
was needed within the common market, both to level the playing field and to limit animal testing. Since then, and revised and strengthened as Directive $2010 / 63 / \mathrm{EU}$, the EU requires that practically available alternatives to animal experiments have to be used (European Parliament, 2010). The EU also tasked the European Commission and the Member States with furthering the development and validation of alternatives. The 2010 Directive continued to expand the scope of the legislation and added enforcements. It also included an important reversal of the burden of proof: the legislation does not restrict the free use of animals in science, but it grants an exemption from the prohibition of animal tests upon sufficient justification (Hartung, 2010a). Noteworthy, the scope of Directive 2010/63/EU was extended to include the entire animal life cycle, from breeding to the conclusion of the experiments; and it was extended to late stages (last trimester) of embryonic development as well as to cephalopods, such as octopus and squid. The legislation also requires the application of the ${ }_{3} R s$ and encourages their further development, as well as requiring the systematic evaluation of projects, including prospective and, for certain experiments, retrospective assessments of pain, suffering, and distress caused to animals.

While these general provisions apply for basic research as well as the applied use of animals for product development and safety testing, it is quite remarkable that the safety testing part (i.e. toxicology) has become the primary battleground over animal experimentation and its alternatives. This area accounts for only about $10 \%$ of overall animal use in science (Daneshian et al., 2015), according to statistics from the $\mathrm{EU}$ and elsewhere; yet, it is probably fair to say that $90 \%$ of the work to develop alternative methods, in the sense of one-for-one replacement, has taken place in this field (see Stephens and Mak, 2013) for a comprehensive look at the history of pursuing alternative methods in toxicology). Consequently, toxicology has a lighthouse function for other areas. If we can substitute for animals in the area of human safety, we can undoubtedly do the same in other areas.

\section{3}

Problems with Animal Models Increasingly Acknowledged

A key recent development is that animal experiments are being challenged on more than just ethical grounds (Hartung, 2017a, b). Animal experimentation is resource intensive, in terms of both expense and duration (Bottini and Hartung, 2009), and we are increasingly realizing the limited predictivity of animal models for humans based on both the limited reproducibility of their results, and the differing results across animal species (Hartung, 2013; Pound et al., 
2004; Pound and Bracken, 2014). Humans are obviously not 7okg rats (Hartung, 2009a). Within toxicology research, the costs have become particularly evident as companies start to tackle the backlog of testing of industrial chemicals under the European Registration, Evaluation, Authorisation and Restriction of CHemicals (REACH) program (Hartung and Rovida, 2009). The comprehensive assessment of a single substance amounts to several million us dollars of testing costs. We simply cannot afford to test tens of thousands of substances using the usual methods, and we also do not even have the laboratory capacities to do so. Often overlooked, we also need about $20 \mathrm{~kg}$ of a substance to run a comprehensive toxicity profile; for novel and costly substances such an amount is often impractical to synthesize.

The most important issue-the limited predictivity of animal experimentation - was underscored by recent findings that the high failure rate of new substances in the pharmaceutical industry is based, at least in part, on the misleading findings of the animal models used during the course of development (Hartung, 2013). Two major assessments by pharmaceutical companies, one by Amgen and one by Bayer, showed that animal-based research studies were reproducible in only $11 \%$ of 53 projects (Begley and Ellis, 2012) and in about $20 \%-25 \%$ of 67 studies (Prinz, Schlange and Asadullah, 2011). This and similar findings have fueled a more general discussion about the reproducibility crisis in science (Baker, 2016). It is important to note that this issue is simply one of replicating the findings of earlier animal studies in later animal studies of similar design; this is quite apart from the issue of extrapolating such results to humans. The reproducibility crisis increasingly calls into question whether animal studies should serve as the ultimate gold standard of scientific work in the life sciences. Indeed, more than $95 \%$ of substances that show promise in animal experiments (Arrowsmith, 2011a, b, 2012) fail in later stages of drug development when assessed in human trials (Hartung, 2013). To be sure, the drug development process continues to deliver new entities but at costs in the billion us dollar range (DiMasi, Grabowski and Hansen, 2016), making it more and more difficult to sustain this business model.

\section{$4 \quad$ Regulatory Testing as a Role Model for Moving Away from Animal Experimentation as a Whole}

A scientific discussion challenging animal experimentation would be fruitless if there were no alternatives. When acknowledging the shortcomings of animal experimentation, many animal researchers will essentially argue that it is better to have something imperfect than nothing at all. But are they 
just imperfect, or are they downright misleading? Nobody knows how many promising drugs have never made it to human trials because the animal tests wrongly sorted them out as inefficient or harmful. It is somewhat frightening to realize that aspirin would probably not make it to the market today because it fails a number of animal-based safety tests (Hartung, 2009b).

As stated above, formal replacement of animal-based procedures by alternatives has been pioneered mainly in the field of regulatory testing, i.e. the toxicological assessment of drugs, medical devices, chemicals, pesticides, cosmetics, and other consumer products prior to marketing, as well as the batch-release testing for vaccines. Why the focus here on alternatives to animal-based tests? Governments tend to fund the development of alternatives to the animal procedures they prescribe (safety sciences); and legislation, such as the European cosmetics test ban (Hartung, 2008) and REACH (Hartung, 2010b), have spurred these developments. Hence, regulatory toxicology has the potential to be an important driver for animal replacement research more generally. Noteworthy, the cosmetic ban was the consequence of public pressure voiced by animal protection groups to policy makers, not a consequence of scientific progress or perceived regulatory needs. Much of the new science came after the legislative ban took effect; and after the ban was embraced by industry and regulators, first in the $\mathrm{EU}$ and then elsewhere.

Regulatory testing has formed a bit of an island because, until recently, it has been outside of the normal competition of ideas, failing to keep pace with technological advances. In contrast, there is pressure to employ the latest technologies in drug development. After patenting a lead compound, there is a race to bring the drug to the market, as a single day of delay costs the company, on average, us $\$ 1$ million to recuperate the almost us $\$ 3$ billion of average development costs (DiMasi et al., 2016). This means that drug development companies readily explore and apply technologies that hasten decision making and may bring a competitive advantage. It has been suggested that our knowledge in these areas doubles every seven years. In comparison, many approaches in regulatory science are decades old: acute and repeateddose testing originate from the 1920s, skin and eye irritation from the 1940s, and reproductive toxicity testing from the 1960s. This unusually static situation has inadvertently allowed the long-term, systematic targeting of these assays in recent decades. In other areas of biomedical research, development and validation projects of 10-20 years (not uncommon in the testing arena) would be quite pointless, because the technology changes so much over time that the validated test becomes obsolete. So, to some extent the development of alternatives for regulatory animal tests has become the sparring partner for other areas of research, as it elucidates general needs for addressing the 
definition and reporting of experiments, their combined use, and their relevance, quality assurance, and validation. This also helps to transform, more generally, the mindset of researchers, creating awareness of the availability and the need of alternatives.

Education plays a key role here. By training the next generation of scientists with an openness to the new technologies and with a critical eye towards the use of animals - certainly not hailing them as the ultimate tool of generating knowledge - the basis for a balanced use of different tools is set (Daneshian et al., 2011; Hartung, Blaauboer and Leist, 2009). Internet-based teaching and training is facilitating this sea change. The emerging professorships for alternative methods in Konstanz, and other places in Germany; Baltimore; Utrecht; and elsewhere, and their collaboration with each other, represent an enormous opportunity. An important element is the parallel replacement of animals in the teaching of all areas of the life sciences. Nowadays, alternative teaching models, computer simulations, and movies can effectively substitute for repeatedly carrying out the same demonstration of an animal test. The non-animal approaches help to underscore a mindset of avoiding animal use. But it is not only about the next generation. Especially important is the continuous education of regulators, which at the moment often form a bottleneck for the broader use of new approaches. Such continuing education plays an important role in accelerating change across all areas of animal-based research.

The obvious principal alternatives to animal use are in vitro and in silico approaches, i.e. methods based on cell culture or on computer modeling. Although not without their own scientific limitations, these approaches can at least be focused on human biology, and they are typically cheaper and faster than animal tests. We also have increasingly technical solutions (Marx et al., 2016) and quality assurance tools (Coecke et al., 2005) to overcome the limitations of the early cell-culture technologies. Stem-cell technologies now make high-quality human cells more broadly available, and bioengineering allows the reproduction of organ architecture and function in cell culture. Such advanced organotypic cell models are now often called microphysiological systems. They promise to provide all life sciences, including safety sciences (Andersen et al., 2014; Marx et al., 2016; Smirnova et al., 2018), with more meaningful functional organ models, overcoming many of the shortcomings of traditional cell culture (Pamies and Hartung, 2017) and, thereby, making them more competitive to animal experimentation. Our own development of human mini-brains from stem cells (Pamies et al., 2017) may serve as an example for the many models mushrooming as a consequence of stem-cell technologies and advances in bioengineering. 
The ultimate quality control and the basis for replacing an animal method is formal validation of alternative methods (Leist et al., 2012). This started with the creation of the first validation body, the European Centre for the Validation of Alternative Methods (ECVAM) in 1991 (which the author headed between 2002 and 2008). Since then, validation has been internationally harmonized and also required for new animal test methods by the Organisation for Economic Co-operation and Development (OECD) (2005). The validation process was developed for regulatory tests (mainly originating from drug safety testing, but with a focus on their application to cosmetics and industrial chemicals), where safety is at stake, and is not generally considered necessary for other areas of the life sciences. However, the elements and principles of validation are very much advisable to any type of experimental work (i.e., the clear definition of the method-its purpose, execution, and applications-and the assessment of its reproducibility and relevance) and are vital to moving away from animal experiments. Successful examples of validation include testing for skin and eye corrosion and irritation, phototoxicity, skin sensitization, pyrogenicity, and batch testing for several vaccines in international test guidelines from the OECD and different pharmacopoeias. The reader is referred to the websites of validation bodies, such as ECVAM and its Us counterpart, the Interagency Coordinating Committee on the Validation of Alternative Methods (ICCVAM); and the independent website, AltTox.org, which keep track of the status of the validation and acceptance of testing methods.

Validation has taught us, first of all, that clear definitions of a test and its purpose are needed. It is astonishing to see how often these are not clearly stated in scientific literature and the whole field of animal research. Second, validation formally addresses reproducibility. While requiring ring trials of a new method is certainly going too far, a more formal reporting on reproducibility (starting with a clear distinction between what was done repeatedly, and what was done in parallel technical replicates only) is an important element of addressing the prevailing reproducibility crisis. The most overlooked element of validation within the life sciences is to formally establish the relevance of a test. This might sound odd to a lay audience, but in science we often produce results in a model system and then uncritically translate them to the system being modeled (usually humans).

Often lacking in our scientific papers are formal assessments of the scientific basis of the new methods (are the relevant mechanisms reflected?) and their interspecies predictivity, as well as a demonstration that the model gives meaningful results with well-known reference compounds. The "cherry-picking" of 
the literature backing our results creates enormous bias. A change in scientific paradigm is needed towards evidence-based approaches. Here too, within the preclinical sciences, it is toxicology and the search for alternatives that are spearheading relevant developments, i.e., the creation of evidence-based toxicology (Hoffmann and Hartung, 2006), with systematic reviews of the literature (Stephens et al., 2016).

Alternative Technologies in Toxicology as a Roadmap for Basic and Applied Research

Much of what has been written above is centered on in vitro methods. In silico methods have undergone similar developments making them a central tool in the life sciences and regulatory assessments (Ekins, 2014). Ever-increasing computer-power allows more and more applications of these methods. However, their limitations so far prohibit regulatory use on a large scale (Hartung and Hoffmann, 2009); this seems to result from the fact that most approaches have looked for an exact formula to describe parts of the chemical universe from the structures of the chemicals. This has proven to be difficult owing to the quality problems of the animal input data and the quite small datasets generally available. More recently, however, in silico methods have gained ground, especially the very pragmatic area of data-gap filling by read-across. Readacross is based on the principle that similar chemicals have similar toxicological effects; i.e., it suggests taking over the results from similar chemicals with the respective reasoning about similar chemistry, chemicophysical properties, uptake, metabolism, and biological effect. The use of read-across flourished in the context of REACH (Patlewicz et al., 2014), but the extent of its applicability and how to conduct and report it are under debate. This has prompted the development of Good Read-Across Practices (Ball et al., 2016) and ideas for a more automated read-across (Hartung, 2016). The latter development also makes use of the emerging large toxicological databases (Luechtefeld et al., 2016). These machine-learning approaches are agnostic to the biological effect studied and are similarly useful in drug discovery. Other in silico approaches, which are mushrooming, include modeling from receptor binding to cells, organs, and organisms. In short, the informatics revolution fuels the replacement of animal tests with increasing pace (Ekins, 2014).

Increasingly, in vitro and in silico methods are combined, forming integrated testing strategies, acknowledging that one method alone does not satisfy all information needs (Hartung et al., 2013; Rovida et al., 2015a). While the idea is rather simple, the systematic composition, optimization, and validation of 
such strategies are still in their infancy. Again, the safety sciences are spearheading the concept, also combining it with a more mechanistic approach (Tollefsen et al., 2014); but the needs and opportunities are not very different for other areas of the life sciences. Mechanistic toxicology has been boosted by the recent cataloging of mechanisms as adverse outcome pathways (AOP) (Leist et al., 2017), which have been systematically developed under the umbrella of the OECD and which help the discussion and design of integrated testing strategies, among others. Similarly, modern drug development integrates different testing tools, though this could often benefit from a more formal integration of tests. It is interesting what can be learned from the mass testing of environmental chemicals. Simply said, for tests, $1+1$ is more than 2 when well integrated.

In the life sciences, the increases in molecular and mechanistic understanding - as exemplified by the mapping of the human genome - have given rise to mechanistic models throughout experimental medicine (Langley et al., 2015). The new approaches do not simply replace or complement animal tests; they are enabling technologies that outperform the animal-based procedures as soon as sufficient mechanistic understanding shows their physiological relevance. The increasing use of non-animal methods corresponds with this stronger mechanistic emphasis of research: biochemistry and molecular biology have dramatically changed how we understand physiology and disease. It is very difficult to identify a mechanism leading to disease in the whole animal organism, and it is very difficult to test selectively for a certain mechanism employed by a test substance using a complex animal model. An understanding of pathways increasingly allows the modeling of (patho-) physiology as a systems biology (systems toxicology) approach (Hartung et al., 2012, 2017, Smirnova et al., 2018). The scientific progress that is demanding more tailored experimental systems has been automatically making animal testing superfluous to needs (Rovida et al., 2015b). Figure 28.1 illustrates these developments.

\section{7 \\ Barriers to Non-animal Methods}

The major obstacle for the development of new non-animal models is the prevailing over-reliance on the value of animal-based procedures as an information source in the life sciences. As long as researchers believe that they cannot produce the high-level publications needed to enhance their career without a new gene knock-out mouse, many researchers will choose animal experiments. A transparent and objective assessment of animal research's shortcomings is, therefore, key for opening the scientific community to change. The reproducibility crisis noted in the life sciences is, therefore, a godsend for those 


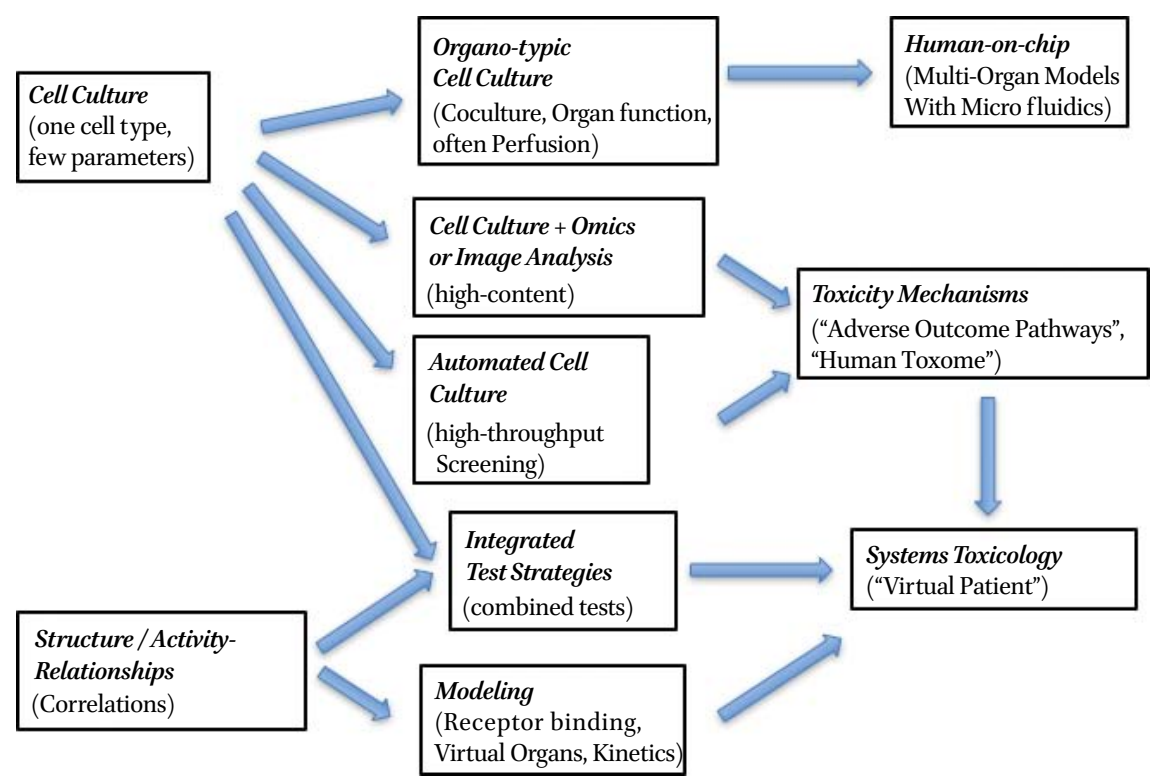

FIGURE 28.1 The technological developments in alternative methods in toxicology (Busquet and Hartung, 2017; reproduced with permission). Technologies listed as today refer to the more broadly available new technologies, while those only emerging are listed as future.

who want such a discussion about the shortcomings and misdirection of animal tests and models.

For decades, our desire to study the complexity of the human organism and its diseases seemed feasible only through using animals. Increasingly, however, very different complex systems are now used. These new approaches challenge the value of costly and time-consuming animal models and erode the justification for causing animal suffering. In vitro and in silico tools are cheaper and faster and, thus, can usually be carried out more readily and with greater ease of quality control. With such quality control, sometimes supported by validation, they represent robust methods for data generation. They are simplistic and partial, i.e. only reflecting a small fraction of (patho-) physiology. However, this is overcome by two principal approaches: reproducing complexity in the models (e.g., [multi-] organs on a chip); and combining pieces of information in integrated testing strategies or modeling (e.g., systems biology). Ultimately, all alternative approaches come with limitations too; but compared to animal models, these limitations can be surmounted by combining these new advanced animal-free models. With the ongoing improvements of these technologies and their (combined) use, 
we will be able to rely less and less on the evidently unsound animal component in this mix.

\section{$8 \quad$ Concluding Thoughts}

Many developments summarized here hint at an upcoming scientific revolution, changing the paradigm and predominance of animal experimentation in the life sciences. In his influential book, The Structure of Scientific Revolutions (1962), Thomas Samuel Kuhn (1922-1996) laid out some principles that nurture this expectation (Hartung, 2008). Our current belief system is being shattered by, among other things, the reproducibility crisis. Kuhn (1962) remarked that "normal science [...] often suppresses fundamental novelties because they are necessarily subversive of its basic commitments" (p. 5); a good description of how alternatives have been perceived by many in the scientific establishment. The revolution takes place when "the tradition-shattering complements to the tradition-bound activity of normal science" (p. 6) hit. This is exactly what we observe with accelerated technological opportunities to transition into mechanistic, cellular, and even molecular understanding. The old (animal) model simply does not fully meet the needs of scientific and economic progress; it fails in cost, speed, level of detail of understanding, and human relevance. On top of this, animal experimentation lacks acceptance by an ethically evolving society. So let us embrace the revolution.

\section{Acknowledgment}

The input and editing by Martin Stephens are gratefully appreciated. The author is aware that many references are only to his own earlier publications; this is not meant to say that others have not published similar ideas, but these publications fully reference them and thus give the interested reader access.

\section{Conflict of Interest Statement}

The author is the Founder of Organome LLC, Baltimore, MD, which aims to make brain organoid technologies from Johns Hopkins University commercially available. He also consults Underwriters Laboratories on computational toxicology, with shares of their respective sales, and consults AstraZeneca on organoid technologies and testing. 


\section{References}

Andersen, M., K. Betts, Y. Dragan, S. Fitzpatrick, J.L. Goodman, T. Hartung, J. Himmelfarb, D.E. Ingber, A. Jacobs, R. Kavlock, K. Kolaja, J.L. Stevens, D. Tagle, D.L. Taylor and D. Throckmorton (2014). Developing Microphysiological Systems for Use as Regulatory Tools: Challenges and Opportunities. Alternatives to Animal Experimentation, 31, pp. 364-367. [online] Available at: http://www.altex.ch/resources/ altex_2014_3_Suppl_Andersen.pdf [Accessed 10 July 2017].

Arrowsmith, J. (2011a). Trial Watch: Phase II Failures: 2008-2010. Nature Reviews Drug Discovery, 10, pp. 328-329.

Arrowsmith, J. (2011b). Trial Watch: Phase III and Submission Failures: 2007-2010. Nature Reviews Drug Discovery, 10, p. 87.

Arrowsmith, J. (2012). A Decade of Change. Nature Reviews Drug Discovery, 11, pp. 17-18.

Baker, M. (2016). 1,500 Scientists Lift the Lid on Reproducibility. Nature, 533, pp. $45^{2-454 .}$

Ball, N., M.T.D. Cronin, J. Shen, M.D. Adenuga, K. Blackburn, E.D. Booth, M. Bouhifd, E. Donley, L. Egnash, J.J. Freeman, C. Hastings, D.R. Juberg, A. Kleensang, N. Kleinstreuer, D. Kroese, A.C. Lee, T. Luechtefeld, A. Maertens, S. Marty, J.M. Naciff, J. Palmer, D. Pamies, M. Penman, A.N. Richarz, D.P. Russo, S.B. Stuard, G. Patlewicz, B. van Ravenzwaay, S. Wu, H. Zhu and T. Hartung (2016). Toward Good Read-Across Practice (GRAP) Guidance. Alternatives to Animal Experimentation, 33, pp. 149-166.

Begley, C.G. and L.M. Ellis (2012). Drug Development: Raise Standards for Preclinical Cancer Research. Nature, 483, pp. 531-533.

Bottini, A.A. and T. Hartung (2009). Food for Thought.... On Economics of Animal Testing. Alternatives to Animal Experimentation, 26, pp. 3-16.

Busquet, F. and T. Hartung (2017). The Need for Strategic Development of Safety Sciences. Alternatives to Animal Experimentation, 34, pp. 3-21.

Coecke, S., M. Balls, G. Bowe, J. Davis, G. Gstraunthaler, T. Hartung, R. Hay, O.W. Merten, A. Price, L. Schechtman, G. Stacey and W. Stokes (2005). Guidance on Good Cell Culture Practice. Alternatives to Laboratory Animals, 33, pp. 261-287.

Daneshian, M., M.A. Akbarsha, B. Blaauboer, F. Caloni, P. Cosson, R. Curren, A. Goldberg, F. Gruber, F. Ohl, W. Pfaller, J. van der Valk, P. Vinardell, J. Zurlo, T. Hartung and M. Leist (2011). A Framework Program for the Teaching of Alternative Methods (Replacement, Reduction, Refinement) to Animal Experimentation. Alternatives to Animal Experimentation, 28, pp. 341-352.

Daneshian, M., F. Busquet, T. Hartung and M. Leist (2015). Animal Use for Science in Europe. Alternatives to Animal Experimentation, 32, pp. 261-274.

DiMasi, J.A., H.G. Grabowski, and R.W. Hansen (2016). Innovation in the Pharmaceutical Industry: New Estimates of R\&D Costs. Journal of Health Economics, 47, pp. $20-33$. 
Ekins, S. (2014). Progress in Computational Toxicology. Journal of Pharmacological and Toxicological Methods, 69, pp. 115-140.

European Parliament (2010). Directive 2010/63/EU of the European Parliament and of the Council of 22 September 2010 on the protection of animals used for scientific purposes. Official Journal of the European Communities, L 276, pp. 33-79. [online] Available at: http://eur-lex.europa.eu/legal-content/EN/TXT/?uri=CELEX\%33 320 10Loo63 [Accessed 18 July 2017].

Hartung, T. (2008). Towards a New Toxicology - Evolution or Revolution? Alternatives to Laboratory Animals, 36, pp. 635-639.

Hartung, T. (2009a). Toxicology for the Twenty-first Century. Nature, 46o, pp. 208-212.

Hartung, T. (2009b). Per Aspirin Ad Astra. Alternatives to Laboratory Animals, 37(2), pp. $45^{-47}$.

Hartung, T. (2010a). Comparative Analysis of the Revised Directive 2010/63/EU for the Protection of Laboratory Animals with Its Predecessor 86/6og/EEC - a t ${ }^{4}$ Report. Alternatives to Animal Experimentation, 27, pp. 285-303.

Hartung, T. (2010b). Food for Thought... On Alternative Methods for Chemical Safety Testing. Alternatives to Animal Experimentation, 27, pp. 3-14.

Hartung, T. (2013). Look Back in Anger - What Clinical Studies Tell Us About Preclinical Work. Alternatives to Animal Experimentation, 30, pp. 75-291.

Hartung, T. (2016). Making Big Sense from Big Data in Toxicology by Read-across. Alternatives to Animal Experimentation, 33, pp. 83-93.

Hartung, T. (2017a). Evolution of Toxicological Science: The Need for Change. International Journal of Risk Assessment and Management, 20, pp. 21-45.

Hartung, T. (2017b). Opinion Versus Evidence for the Need to Move Away from Animal Testing. Alternatives to Animal Experimentation, 34, pp. 193-200.

Hartung, T. and S. Hoffmann (2009). Food for Thought..... On In Silico Methods in Toxicology. Alternatives to Animal Experimentation, 26, pp. 155-166.

Hartung, T. and C. Rovida (2009). Chemical Regulators Have Overreached. Nature, 46o, pp. $1080-1081$.

Hartung, T., B. Blaauboer and M. Leist (2009). Food for Thought.... On Education in Alternative Methods in Toxicology. Alternatives to Animal Experimentation, 26, pp. $255^{-263}$.

Hartung, T., R. FitzGerald, P. Jennings, G. Miriams, M. Peitsch, A. Rostami-Hodjegan, I. Shah, M. Wilks and S. Sturla (2017). Systems Toxicology: Real World Applications and Opportunities. Chemical Research in Toxicology, 30, pp. 870-882.

Hartung, T., T. Luechtefeld, A. Maertens and A. Kleensang (2013). Integrated Testing Strategies for Safety Assessments. Alternatives to Animal Experimentation, 30, pp. $3^{-18 .}$

Hartung, T., E. van Vliet, J. Jaworska, L. Bonilla, N. Skinner and R. Thomas (2012). Systems Toxicology. Alternatives to Animal Experimentation, 29, pp. 119-128. 
Hoffmann, S. and T. Hartung (2006). Towards an Evidence-based Toxicology. Human and Experimental Toxicology, 25, pp. 497-513.

Kuhn, T. (1962). The structure of scientific revolutions. Chicago, IL: University of Chicago Press.

Langley, G., C.P. Austin, A.K. Balapure, L.S. Birnbaum, J.R. Bucher, J. Fentem, S.C. Fitzpatrick, J.R. Fowle III, R.J. Kavlock, H. Kitano and B.A. Lidbury (2015). Lessons from Toxicology: Developing a 21st Century Paradigm for Medical Research. Environmental Health Perspectives, 123(11), p. A268.

Leist, M., A. Ghallab, R. Graepel, R. Marchan, R. Hassan, S. Hougaard Bennekou, A. Limonciel, M. Vinken, S. Schildknecht, T. Waldmann, E. Danen, B. van Ravenzwaay, H. Kamp, I. Gardner, P. Godoy, F.Y. Bois, A. Braeuning, R. Reif, F. Oesch, D. Drasdo, S. Höhme, M. Schwarz, T. Hartung, T. Braunbeck, J. Beltman, H. Vrieling, F. Sanz, A. Forsby, D. Gadaleta, C. Fisher, J. Kelm, D. Fluri, G. Ecker, B. Zdrazil, A. Terron, P. Jennings, B. van der Burg, S. Dooley, A.H. Meijer, E. Willighagen, M. Martens, C. Evelo, E. Mombelli, O. Taboureau, A. Mantovani, B. Hardy, B. Koch, S. Escher, C. van Thriel, C. Cadenas, D. Kroese, B. van de Water, and J.G. Hengstler (2017). Adverse Outcome Pathways: Opportunities, Limitations and Open Questions. Archives Toxicology, 31, pp. 221-229.

Leist, M., M. Hasiwa, M. Daneshian and T. Hartung (2012). Validation and Quality Control of Replacement Alternatives - Current Status and Future Challenges. Toxicological Research, 1, pp. 8-22.

Luechtefeld, T., A. Maertens, D.P. Russo, C. Rovida, H. Zhu and T. Hartung (2016). Global Analysis of Publicly Available Safety Data for 9,801 Substances Registered Under REACH from 2008-2014. Alternatives to Animal Experimentation, 33, pp. 95-109.

Marx, U., T.B. Andersson, A. Bahinski, M. Beilmann, S. Beken, F.R. Cassee, M. Cirit, M. Daneshian, S. Fitzpatrick, O. Frey, C. Gaertner, C. Giese, L. Griffith, T. Hartung, M.B. Heringa, J. Hoeng, W.H. de Jong, H. Kojima, J. Kuehnl, A. Luch, I. Maschmeyer, D. Sakharov, A.J.A.M. Sips, T. Steger-Hartmann, D.A. Tagle, A. Tonevitsky, T. Tralau, S. Tsyb, A. van de Stolpe, R. Vandebriel, P. Vulto, J. Wang, J. Wiest, M. Rodenburg and A. Roth (2016). Biology-inspired Microphysiological System Approaches to Solve the Prediction Dilemma of Substance Testing Using Animals. Alternatives to Animal Experimentation, 33, pp. 272-321.

Organisation for Economic Co-operation and Development (OECD) (2005). Guidance Document on the Validation and International Acceptance of New or Updated Test Methods for Hazard Assessment. OECD Series on Testing and Assessment, 34. [online] Available at: http://www.oecd.org/officialdocuments/publicdisplay documentpdf/?doclanguage $=$ en $\&$ cote $=$ env $/$ jm $/$ mono(2005) 14 [Accessed 16 June 2017].

Pamies, D. and T. Hartung (2017). 21st Century Cell Culture for 21st Century Toxicology. Chemical Research in Toxicology, 30, pp. 43-52. 
Pamies, D., P. Barreras, K. Block, G. Makri, A. Kumar, D. Wiersma, L. Smirnova, C. Zang, J. Bressler, K.M. Christian, G. Harris, G.L. Ming, C. Berlinicke, K. Kyro, H. Song, C.A. Pardo, T. Hartung and H.T. Hogberg (2017). A Human Brain Microphysiological System Derived from Induced Pluripotent Stem Cells to Study Neurological Diseases and Toxicity. Alternatives to Animal Experimentation, 34(3), pp. 362-367.

Patlewicz, G., N. Ball, R.A. Becker, K. Blackburn, E. Booth, M. Cronin, D. Kroese, D. Steup, B. van Ravenzwaay and T. Hartung (2014). Read-across Approaches: Misconceptions, Promises and Challenges Ahead. Alternatives to Animal Experimentation, 31, pp. 387-396.

Pound, P. and M.B. Bracken (2014). Is Animal Research Sufficiently Evidence Based to Be a Cornerstone of Biomedical Research? British Medical Journal, 348, p. g3387. [online] Available at: http://doi.org/10.1136/bmj.g3387 [Accessed 10 July 2017].

Pound, P., S. Ebrahim, P. Sandercock, M.B. Bracken and I. Roberts (2004). Where Is the Evidence That Animal Research Benefits Humans? British Medical Journal, 328(7438), pp. 514-517.

Prinz, F., T. Schlange and K. Asadullah (2011). Believe It or Not: How Much Can We Rely on Published Data on Potential Drug Targets?. Nature Reviews Drug Discovery, 10, p. 712 [online] Available at: https://www.nature.com/articles/nrd3439-c1 [Accessed 10 July 2017].

Rovida, C., N. Alépée, A.M. Api, D.A. Basketter, F.Y. Bois, F. Caloni, E. Corsini, M. Daneshian, C. Eskes, J. Ezendam, H. Fuchs, P. Hayden, C. Hegele-Hartung, S. Hoffmann, B. Hubesch, M.N. Jacobs, J. Jaworska, A. Kleensang, N. Kleinstreuer, J. Lalko, R. Landsiedel, F. Lebreux, T. Luechtefeld, M. Locatelli, A. Mehling, A. Natsch, J.W. Pitchford, D. Prater, P. Prieto, A. Schepky, G. Schuurmann, L. Smirnova, C. Toole, E. van Vliet, D. Weisensee and T. Hartung (2015a). Integrated Testing Strategies (ITS) for Safety Assessment. Alternatives to Animal Experimentation, 32, pp. 171-181.

Rovida, C., C. Asakura, M. Daneshian, H. Hofman-Huether, M. Leist, L. Meunier, D. Reif, A. Rossi, M. Schmutz, J.P. Valentin, J. Zurlo and T. Hartung (2015b). Toxicity Testing in the 21st century Beyond Environmental Chemicals. Alternatives to Animal Experimentation, 32, pp. 25-40.

Smirnova, L., N. Kleinstreuer, R. Corvi, A. Levchenko, S.C. Fitzpatrick, and T. Hartung (2018). 3S: Systematic, Systemic, and Systems Biology and Toxicology. Alternatives to Animal Experimentation, 35, pp. 39-162.

Stephens, M. and N. Mak (2013). History of the ${ }_{3}$ Rs in toxicity testing: From Russell and Burch to 21st century toxicology. In: D.G. Allen and M.D. Waters, eds., Reducing, Refining and Replacing the Use of Animals in Toxicity Testing. 19th ed. Royal Society of Chemistry. pp. 1-43. 
Stephens, M.L., K. Betts, N.B. Beck, V. Cogliano, K. Dickersin, S. Fitzpatrick, J. Freeman, G. Gray, T. Hartung, J. McPartland, A.A. Rooney, R.W. Scherer, D. Verloo and S. Hoffmann (2016). The Emergence of Systematic Review in Toxicology. Toxicological Sciences, 152, pp. 10-16.

Tollefsen, K.E., S. Scholz, M.T. Cronin, S.W. Edwards, J. de Knecht, K. Crofton, N. GarciaReyero, T. Hartung, A. Worth and G. Patlewicz (2014). Applying Adverse Outcome Pathways (AOPs) to Support Integrated Approaches to Testing and Assessment (IATA). Regulatory Toxicology and Pharmacology, 7o, pp. 629-640. 